\title{
A pilot study on a new model for the study of patient-perceived quality of life in the surgical treatment of PAOD: the Surgical Peripheral Artery Disease Interview questionnaire
}

\author{
Elena GIACOMELLI ${ }^{1}$, Bastianina CONTENA ${ }^{2}$, Raffaele PULLI ${ }^{3}$, \\ Walter DORIGO ${ }^{1 *}$, Stefano TADDEI ${ }^{2}$, Carlo PRATESI ${ }^{1}$
}

\begin{abstract}
${ }^{1}$ Department of Vascular Surgery, University of Florence, Florence, Italy; ${ }^{2}$ Psychology and Psychiatry Unit, Department of Health Sciences, University of Florence, Florence, Italy; ${ }^{3}$ Department of Vascular Surgery, University of Bari, Bari, Italy

*Corresponding author: Walter Dorigo, Department of Vascular Surgery, University of Florence, Largo Brambilla 3, 50134 Florence, Italy. E-mail: dorigow@unifi.it
\end{abstract}

\section{A B S T R A C T}

BACKGROUND: The aim of this study was to develop a structured interview for functional evaluation of surgical treatment of peripheral arterial obstructive disease (PAOD), in terms of postoperative quality of life (QoL), including both the constructs already present in the literature and the ones derivable from direct clinical experience.

METHODS: We identified the most relevant constructs, including physical symptoms (PS), discomfort with bodily integrity (DBI), satisfaction for care (SC), impact on daily life (IDL) and social functioning (SF). We developed an 11-item questionnaire with answers on 5 points to be administered in form of structured interview by physicians, namely the Surgical Peripheral Artery Disease Interview (SPADI). A pilot administration of the interview was performed in 30 patients undergone femoro-popliteal bypass for PAOD in the previous months.

Data were collected in a specific answer form, containing also information about the patients, the risk factors, the kind of treatment and the follow-up outcomes.

RESULTS: We found excellent correlations between items and theoretical constructs. The exploratory factor analysis confirms four constructs, with functioning composed by impact on daily life and social functioning. The internal consistency of scales was good. The indices of physical and mental functioning were similar to those of general population. Data showed a low level of aggression, depression, tension, confusion and fatigue, confirmed by the results of Self Rating Depression Scale. About SPADI items, PS was in the average range, while DBI seemed to be almost absent; SC was good and, in the postoperative setting, patients perceived themselves as efficient (IDL) and their SF appeared to be good. CONCLUSIONS: In this preliminary study, SPADI was able to investigate dimensions that were not considered before and it may become a useful tool for supporting surgeons to an even more effective management of PAOD. Prospective validation of this questionnaire is mandatory.

(Cite this article as: Giacomelli E, Contena B, Pulli R, Dorigo W, Taddei S, Pratesi C. A pilot study on a new model for the study of patient-perceived quality of life in the surgical treatment of PAOD: the Surgical Peripheral Artery Disease Interview questionnaire. Ital J Vasc Endovasc Surg 2017;24:29-34. DOI: 10.23736/S1824-4777.17.01287-6)

Key words: Peripheral arterial disease - Operative surgical procedures - Quality of life - Surveys and questionnaires.

$\mathrm{Q}$ uality of life (QoL) is a complex concept that refers to quality of one's life conditions, satisfaction with life conditions and a combination of both. ${ }^{1}$ Some authors ${ }^{2}$ suggested the need to separately define QoL and health-related QoL (HR-QoL). HR-QoL refers to physical, psychological and social domains regarding health and are influenced by personal experiences, attitudes and perceptions.

As far as a patient-based evaluation of QoL is concerned, the use of specific instruments has been recently 


\section{COPYRIGHT $^{(} 2017$ EDIZIONI MINERVA MEDICA}

advocated. In the daily practice, it would be useful to administer a generic questionnaire of QoL associated to a specific instrument to estimate QoL associated with a specific disease. The most generic instrument widely used is the Short-Form 36 Health Survey (SF-36), or its shorter form (SF-12), which is easier to fill in. ${ }^{3}$

In this regard, in recent years particular attention has been paid to the QoL of patients with peripheral artery occlusive disease (PAOD).

The most specific questionnaire for PAOD is the CLAU-S, because of its validity, reliability and availability in several languages. ${ }^{4}$ However, CLAU-S and the other specific instruments do not seem to fit the characteristics of surgical and postoperative conditions. ${ }^{5}$ Moreover, they are not validated for the Italian language, thus limiting their applicability.

In fact, with the widespread diffusion of endovascular methods, many studies have focused on the results of this kind of treatment, as exemplified by the study of Spertus, ${ }^{6}$ who firstly developed a specific questionnaire. However, few studies investigate the impact of classical surgery on QoL, even if it still represents the gold-standard for complex peripheral lesions.

The aim of our pilot study is to identify a specific instrument to evaluate the QoL in patients undergoing open vascular surgery for PAOD.

\section{Materials and methods}

\section{SPADI definition}

SPADI is the acronym for Surgical Peripheral Artery Disease Interview. Starting from the analysis of the instruments commonly used for the evaluation of QoL in the different diseases, particularly in PAOD, we identified the most relevant constructs of this topic. We highlighted the role of physical symptoms (PS), satisfaction for care (SC), impact on daily life (IDL) and social functioning (SF). Moreover, clinical experience suggests the importance of the Discomfort with the Bodily Integrity (DBI) due to vascular surgery. We developed an interview to be administered by physicians, including 16 questions on Likert Scale from 1 (negative pole) to 5 (positive pole); visual analogue scales were prepared to help patients in their answers.

Examined PS were the presence of burning pain, of paresthesias, of leg swelling and the perception of pins and needles at the operated limb. The patients were asked to assess the differences between pre- and postoperative symptoms, the frequency and the intensity of postoperative symptoms, and their frequency at rest. Considering DBI, items investigate whether discomfort associated with the presence of a scar does exist; discomfort related to the fact that others can see the scar and discomfort related to the idea of having a bypass graft in the body. Three items evaluate SC; one related to the completeness of physician's explanations, one on the surgical treatment and the last one on the therapy in general. IDL is measured by two items regarding difficulties in daily activities and feeling disheartened. SF is measured by three questions regarding the possibility to have hobbies, social relationships and working activities. Furthermore, we have included an item on future perspective.

\section{Procedures}

In order to evaluate the reliability of the interview we inserted items of the SF-12, and we used Self-Rating Depression Scale ${ }^{7}$ and Profile of Mood State 8 to evaluate the clinical aspects related to the mood.

In order to verify the quality of the items we proceeded to an analysis of the correlations between the items of each single construct. To eliminate redundancy and non-specificity between all items we have admitted only those with an inter-item correlation of at least 0.50 or greater than 0.95 .

\section{Patients}

A pilot interview was performed in 30 patients who had undergone a femoro-popliteal bypass graft for PAOD during 2013. Patients were called on the phone and were later invited to have a clinical evaluation at the Department of Vascular Surgery, where, after the administration of the informed consent, the interview was carried out. Data were collected in a database containing also general information about the patient (sex, date of birth, preoperative Rutherford class, risk factors), treatment (date and type of the intervention) and follow-up.

\section{Statistical analysis}

Statistical analysis was performed using a dedicated software (SPSS v. 22.0 Statistics, IBM Corp., Chicago, IL, USA). General characteristics were analyzed using descriptive statistics; differences between means were 


\section{COPYRIGHT ${ }^{(} 2017$ EDIZIONI MINERVA MEDICA}

SPADI QUESTIONNAIRE ON PAOD PATIENTS' QOL

GIACOMELLI

calculated by the method of Student's test. Statistical significance was defined as a P value $<0.05$. Regarding the construction of the instrument, to examine the correlation between items we calculated the linear correlation coefficients (Pearson's $r$ ). Moreover, considering the type of our study, we decided to perform a factor analysis with the principal components method and promax rotation, which has allowed us to detect latent constructs. We have used Cronbach's alpha to assess the internal consistency of the scales.

\section{Results}

\section{SPADI validation}

Analyzing the 16 items of SPADI, regarding the PS construct, the inter-items correlations highlighted the relevance of frequency $(r=0.54)$ and intensity $(r=0.54)$, while the comparison between pre- and postoperative symptoms and the frequency at rest were not significant.

With regard to DBI, the question on the idea of having a bypass was not significant while both items concerning the discomfort due to the scar showed a good correlation $(r=0.91)$.

Considering the construct SC, the correlation analysis suggested the elimination of the items related to the satisfaction for medical explanations for non-specificity, and treatment and therapy in general appeared to be redundant (0.98); however, the item related to the satisfaction for the surgical treatment showed a significant positive correlation with the future perspective, thereby indicating that these two items can detect the construct of SC. IDL appeared to be well represented by items designed to detect obstacles in daily activities and the impact on the emotional tone. The construct of SF was well related with the three items designed for hobbies, relationships and work. According with these results we eliminated 5 non-specific or redundant items and definitively the SPADI was composed by 11 items.

Starting from the analysis of inter-item correlations we calculated scales and verified the item-construct correlations which were all excellent (Table I).

An explorative factor analysis (EFA) using the method of principal components analysis was carried out. To allow greater readability of results orthogonal rotation axis type Promax was adopted. EFA allowed to highlight the presence of four factors explaining a good portion of variance $(84 \%)$ represented by PS, DBI, SC and Functioning, composed by IDL and SF. The Cronbach's alpha of the scales showed good internal consistency, being always higher than 0.60 (Table II). The importance of differentiating IDL from SF of the patients suggested to check the internal consistency of these constructs, which, being both high, allows us to keep separate scales.

\section{Study group}

Patients were predominantly male $(\mathrm{N} .=27,90 \%)$ with a mean age of 68 years (range 50-79). The mean age was higher in women (mean $73.1 \pm 1$ years) than in men (mean $67.8 \pm 6$ years).

Concerning the preoperative Rutherford class, 16 patients $(53.3 \%)$ were in Class 3, 12 patients $(40 \%)$ in class 4,1 patient $(3.3 \%)$ in class 5 and 1 patient $(3.3 \%)$ in class 6 . The main risk factors are listed in Table III.

TABLE I.-Item-construct correlations.

\begin{tabular}{|c|c|c|c|c|c|}
\hline & Physical symptoms & $\begin{array}{l}\text { Discomfort with the } \\
\text { bodily integrity }\end{array}$ & Satisfaction for care & Impact on daily life & Social functioning \\
\hline Frequency & $0.92 *$ & & & & \\
\hline Intensity & $0.83 *$ & & & & \\
\hline Scar_1 & & $0.98 *$ & & & \\
\hline Scar_2 & & $0.98^{*}$ & & & \\
\hline Satisfaction for care & & & $0.89 *$ & & \\
\hline Future perspective & & & $0.91 *$ & & \\
\hline Impact on daily life & & & & $0.90^{*}$ & \\
\hline Depression & & & & $0.90 *$ & \\
\hline Hobbies & & & & & $0.93 *$ \\
\hline Relationships & & & & & $0.90^{*}$ \\
\hline Job & & & & & $0.97 *$ \\
\hline
\end{tabular}




\section{COPYRIGHT $^{(} 2017$ EDIZIONI MINERVA MEDICA}

GIACOMELLI

SPADI QUESTIONNAIRE ON PAOD PATIENTS' QOL

TABLE II.—Explorative factor analysis: factor loadings.

\begin{tabular}{|c|c|c|c|c|c|}
\hline & Physical symptoms & $\begin{array}{l}\text { Discomfort with the } \\
\text { bodily integrity }\end{array}$ & Satisfaction for care & Impact on daily life & Social functioning \\
\hline Cronbach's $\alpha$ & 0.67 & 0.95 & 0.77 & 0.77 & 0.92 \\
\hline Frequency & 1.02 & & & & \\
\hline Intensity & 0.69 & & & & \\
\hline Scar_1 & & 0.98 & & & \\
\hline Scar_2 & & 0.94 & & & \\
\hline Satisfaction for care & & & 1.07 & & \\
\hline Future perspective & & & 0.56 & & \\
\hline Impact on daily life & & & & 0.90 & \\
\hline Depression & & & & 0.75 & \\
\hline Hobbies & & & & & 0.87 \\
\hline Relationships & & & & & 0.91 \\
\hline Job & & & & & 1.02 \\
\hline
\end{tabular}

TABLE III.--Risk factors among patients.

\begin{tabular}{ll}
\hline Risk Factors & N. (\%) \\
\hline Hypertension & $3(10 \%)$ \\
Hypertension and dyslipidemia & $5(17 \%)$ \\
Hypertension and smoking & $6(20 \%)$ \\
Hypertension, dyslipidemia and smoking & $6(20 \%)$ \\
Hypertension, dyslipidemia, smoking and CAD & $1(3 \%)$ \\
Hypertension, dyslipidemia and diabetes & $1(3 \%)$ \\
Hypertension, dyslipidemia, diabetes and CAD & $4(14 \%)$ \\
CAD and smoking & $1(3 \%)$ \\
CAD and dyslipidemia & $1(3 \%)$ \\
\hline CAD: coronary artery disease. & \\
\hline
\end{tabular}

As far as the kind of surgery is concerned, 11 patients (34.5\%) underwent a bypass graft with autologous saphenous vein, the remaining $19(65.5 \%)$ a prosthetic bypass with heparin-bonded expanded polytetrafluorethylene (ePTFE) graft (Propaten ${ }^{\circledR}$ Graft, W.L. Gore \& Associates, Flagstaff, AZ, USA). Additional procedures were performed in 8 cases $(26.6 \%)$ including 3 iliac stenting, 4 vein patches of the distal anastomosis, and one endarterectomy of the common femoral artery.

All but one bypass grafts were patent at the follow-up (max. 24 months); one patient developed bypass occlusion at 3 months.

\section{Analysis of $Q o L$}

Concerning data obtained from the subject's responses to the SF-12, the indices of physical (PC) and mental (MC) functioning showed a level of functioning below the average of the general Italian population; ${ }^{9}$ however, when we consider the average by age of individuals, PC index was in the middle range, and $\mathrm{MC}$ index was good.
TABLE IV.-Descriptive statistics (minimum, maximum, and mean score) of questionnaires.

\begin{tabular}{llllc}
\hline Questionnaire & Scales & Min & Max & Mean \pm SD \\
\hline SPADI & Physical symptoms & 3 & 10 & $5.65 \pm 2.00$ \\
& $\begin{array}{l}\text { Discomfort with } \\
\text { bodily integrity }\end{array}$ & 2 & 10 & $9.17 \pm 1.73$ \\
& Satisfaction for care & 2 & 10 & $7.86 \pm 2.20$ \\
& Impact on daily life & 3 & 10 & $7.65 \pm 2.24$ \\
& Social functioning & 3 & 15 & $11.21 \pm 3.59$ \\
SF-12 & Physical health & 26.00 & 58.34 & $43.52 \pm 10.30$ \\
& Mental health & 13.65 & 66.24 & $49.02 \pm 12.47$ \\
Self-Rating & Depression & 41 & 57 & $47.72 \pm 4.09$ \\
Depression Scale & & & & \\
POMS & Anger-hostility & 1 & 5 & $3.72 \pm 1.16$ \\
& Depression & 1 & 5 & $3.90 \pm 1.23$ \\
& Vigor-activity & 1 & 4 & $2.97 \pm 0.86$ \\
& Tension-anxiety & 1 & 5 & $3.52 \pm 1.09$ \\
& Fatigue & 1 & 5 & $3.59 \pm 1.12$ \\
& Confusion- & 1 & 5 & $4.14 \pm 0.99$ \\
& bewilderment & & & \\
\hline
\end{tabular}

The emotional functioning and the analysis of the POMS scores highlighted a low level of aggression, depression, tension, fatigue, and confusion; conversely, there was a good presence of vigor.

In line with these results, the index of depression detected by the Self-Rating Depression Scale showed the absence of depressive illness in the participants.

As far as SPADI concerned, the impact of PS was in average levels, while DBI seemed to be almost absent; $\mathrm{SC}$ was good and in the postoperative condition, patients seemed to perceive themselves as efficient (IDL). Also, the SF of patients appeared to be good (Table IV).

Concerning SPADI dimensions, it was also possible to detect a statistically significant relationship between SF and IDL indicating that patients who perceived mi- 
TABLE V.-Inter-construct correlations.

\begin{tabular}{|c|c|c|c|c|c|}
\hline & $\begin{array}{l}\text { Physical } \\
\text { symptoms } \\
\text { (PS) }\end{array}$ & $\begin{array}{l}\text { Discomfort } \\
\text { with the } \\
\text { bodily } \\
\text { integrity } \\
\text { (DIB) }\end{array}$ & $\begin{array}{l}\text { Satisfaction } \\
\text { for care } \\
\text { (SC) }\end{array}$ & $\begin{array}{l}\text { Impact on } \\
\text { daily life } \\
\text { (IDL) }\end{array}$ & $\begin{array}{l}\text { Social } \\
\text { functioning } \\
\text { (SF) }\end{array}$ \\
\hline PS & 1 & 0.14 & $0.53 *$ & $0.49 *$ & 0.35 \\
\hline DIB & & 1 & 0.01 & 0.08 & 0.37 \\
\hline $\mathrm{SC}$ & & & 1 & $0.63 *$ & $0.51 *$ \\
\hline IDL & & & & 1 & $0.82 *$ \\
\hline $\mathrm{SF}$ & & & & & 1 \\
\hline
\end{tabular}

nor difficulties in daily activities felt better adapted to social life $(r=0.82)$, considering the direction of scales. Similarly, there was a positive relationship between SC, IDL $(r=0.63)$ and SF $(r=0.51)$, meaning that those patients who were more satisfied for care, showed fewer impediments in everyday life and had better social life. The PS seemed to be related with SC $(r=0.53)$, indicating that satisfaction for care was greater when the perception of symptoms was low (Table V).

\section{Discussion}

The debate on QoL has ancient origins: Aristotle, for example, treated it in the Nicomachean Ethics 10 using the concept of eudaimonia, literally the status of a "good spirit." In the recent literature, we find terms used in an equivalent manner as "health," "subjective wellbeing", "life satisfaction."

Recently, a consensus has been reached on the fact that quality of life should also include character of subjectivity and multidimensionality. Knipfer et al. ${ }^{11}$ reported that the simultaneous application of a generic questionnaire and a disease-specific one is useful to assess the quality of subjective health, too; moreover it is clear that in this way sensitivity is higher than with the exclusive use of a generic questionnaire.

QoL therefore plays a key role in the assessment of surgical outcomes: it is well known that in the clinical practice outcomes are classically represented by technical success and patency; on the other hand, patients usually measure the "success" of an intervention on the perception of changes in physical, psychological and social aspects of their lives. Consequently, the assessment of QoL makes it possible to investigate the actual results of the surgery, overcoming the limits of the traditional data collected from ankle-brachial index (ABI) ${ }^{12}$ and Doppler evaluation, supporting surgeons to implementing a more effective management and treatment of the disease. ${ }^{13}$

Recently, in the broad field of vascular disorders, great importance has been given to the measurement of QoL of patients, in order to assess the outcomes of available medical procedures. ${ }^{14}$ In the USA, the Department of Health indicated the improvement of QoL as a specific objective of the treatment of PAOD, and consequently Pharmaceutical Companies have introduced the collection of this data in the protocols for the evaluation of their medical products too.

Several questionnaires have been proposed in recent years, to specifically evaluate QoL in patients with PAOD. We have already cited in the introduction the CLAU-S; more recently, QoL has been evaluated also in the BASIL trial, ${ }^{15}$ using the VascuQoL questionnaire, which is now validated in The United Kingdom and Northern Europe. 16, 17

In Italy, a specific questionnaire for PAOD does not exist, and the translated instruments are still not validated for Italian language. This fact significantly reduces the applicability of the existing instruments to our everyday practice; as an example, the existing questionnaires measure the walking distance in blocks, while in our country such a definition is not used as a unit of measure. Based on this situation, and considering that there is a lack of questionnaires regarding postoperative QoL and the impact of open surgical procedures on it, we created an Italian-based instrument, trying to assess its applicability in the everyday clinical practice.

The results obtained with this our first study can be the basis for further developments of this instrument.

We identified a total of 11 items, two of which are related to the presence of physical symptoms specifically due to the postoperative surgical conditions, two to the discomfort felt toward the bodily integrity, two related to the satisfaction with care, two to the impact on everyday life and three to the social functioning.

Similarly, we revised response scales, limiting the variability and identifying only two of them, applicable to the entire interview. The identification of a reasonable number of items and answers allowed us to overcome the limitations due to the excessive length of the proposed material, having an instrument that is sufficiently flexible to be administered in the form of an interview over the phone or in person. The modality of the interview is a further element of innovation compared 


\section{COPYRIGHT $^{(} 2017$ EDIZIONI MINERVA MEDICA}

GIACOMELLI

SPADI QUESTIONNAIRE ON PAOD PATIENTS' QOL

to the commonly used tools, and allows submitting the interview to patients of different ages and with different level of literacy.

\section{Limitations of the study}

Our study still carries several limitations. The low number of patients enrolled and the low number of procedures do not allow us to draw final conclusions. In addition to this, an external validation of databases containing a larger number of cases is recommended, such as a prospective validation of the questionnaire. However, starting from these encouraging results, we may propose an innovative instrument suitable for assessing the quality of life in patients undergoing surgery for peripheral arterial disease.

\section{Conclusions}

The existing questionnaires do not assess the most important consequences of PAOD and the outcomes of medical interventions for this disease are usually not considered in the general evaluation of QoL. From this preliminary study, SPADI appeared to be able to investigate dimensions that were not considered before and it may become an useful tool for supporting surgeons to an even more effective management of PAOD. Prospective validation of the questionnaire is mandatory

\section{References}

1. Felce D, Perry J. Quality of life: its definition and measurement. Res Dev Disabil 1995;16:51-74.

2. Hickey A, Barker M, McGee H, O’Boyle C. Measuring health-related quality of life in older patient populations: a review of current approaches. Pharmacoeconomics 2005;23:971-93.
3. Ware J Jr, Kosinski M, Keller SD. A 12-Item Short-Form Health Survey: Construction of Scales and Preliminary Tests of Reliability and Validity. Medical Care 1996;34:220-3.

4. Marquis $\mathrm{P}$, Comte $\mathrm{S}$, Lehert P. International validation of the CLAU$\mathrm{S}$ quality-of-life questionnaire for use in patients with intermittent claudication. Pharmacoeconomics 2001;19:667-77.

5. Mehta T, Venkata Subramaniam A, Chetter I, McCollum P. Diseasespecific quality of life assessment in intermittent claudication: review. Eur J Vasc Endovasc Surg 2003;25:202-8.

6. Spertus J, Jones P, Poler S, Rocha-Singh K. The Peripheral Artery Questionnaire: a new disease-specific health status measure for patients with peripheral arterial disease. Am Heart J 2004;147:301-8.

7. Zung WW. A Self-Rating Depression Scale. Arch Gen Psychiatry $1965 ; 12: 63-70$.

8. Farnè M, Sebellico A, Gnugnoli D, Corallo A. Profile of mood states. Florence: Giunti Editore; 1991.

9. Apolone G. Mosconi P, Quattrociocchi L, Granicolo EAL, Groth N, Ware JE. Questionario sullo stato di salute SF-12. Versione Italiana. Istituto di Ricerche Farmacologiche. Milan: Mario Negri; 2005.

10. Aristotle. Etica nichomachea. Bari: Laterza Editore; 2005.

11. Knipfer E, Reeps C, Dolezal C, Zimmermann A, Pelisek J, Behrens J, et al. Assessment of generic and disease-specific health-related quality of life instruments in peripheral arterial disease. Vasa 2008;37:99115.

12. Lozano FS, March JR, González-Porras JR, Carrasco E, Lobos JM, Ros E. Relative value of the Ankle-Brachial Index of intermittent claudication. Int J Clin Pract 2014;68:1478-82.

13. Goldwurm GF, Baruffi M, Colombo F. Qualità della vita e benessere psicologico. Aspetti comportamentali e cognitivi del vivere felice. Milan; McGraw-Hill; 2004.

14. Strandness DE Jr, Dalman RL, Panian S, Rendell MS, Comp PC, Zhang $\mathrm{P}$, et al. Effect of cilostazol in patients with intermittent claudication: a randomized, double-blind, placebo-controlled study. Vasc Endovascular Surg 2002;36:83-91.

15. Bradbury AW, Adam DJ, Bell J, Forbes JF, Fowkes FG, Gillespie I, et al. Bypass versus Angioplasty in Severe Ischaemia of the Leg (BASIL) trial: An intention-to-treat analysis of amputation-free and overall survival in patients randomized to a bypass surgery-first or a balloon angioplasty-first revascularization strategy. J Vasc Surg 2010;51(Suppl 5):5S-17S

16. Nordanstig J, Wann-Hansson C, Karlsson J, Lundström M, Pettersson M, Morgan MB. Vascular Quality of Life Questionnaire-6 facilitates health-related quality of life assessment in peripheral arterial disease. J Vasc Surg 2014;59:700-7.

17. Nordanstig J, Taft C, Hensäter M, Perlander A, Osterberg K, Jivegård L. Improved Quality of Life After 1 Year With an Invasive Versus a Noninvasive Treatment Strategy in Claudicants: One-Year Results of the Invasive Revascularization or Not in Intermittent Claudication (IRONIC) Trial. Circulation 2014;130:939-47.

Conflicts of interest.-The authors certify that there is no conflict of interest with any financial organization regarding the material discussed in the manuscript. Manuscript accepted: May 31, 2017. - Manuscript received: May 26, 2017. 